\title{
Bullying at Work and Its Impact on Job Satisfaction: An Exploration of School Psychologists
}

\author{
Laura M. Crothers \\ Duquesne University \\ John Lipinski \\ Indiana University of Pennsylvania \\ Taylor Steeves \\ Duquesne University \\ Brianna Drischler \\ Duquesne University \\ Ara J. Schmitt \\ Duquesne University \\ Tammy L. Hughes \\ Duquesne University \\ Angela Fidazzo \\ Duquesne University \\ Jacob Wadsworth \\ Duquesne University
}

\begin{abstract}
Given the persistent national shortage of school psychologists, as well as their job retention concerns, likely related to burnout, it is necessary to examine any factors that negatively impact school psychologists' job satisfaction. In this sample of 94 Pennsylvania school psychologists, the experience of being bullied at work was associated with diminished job satisfaction. Specifically, the independent variables of being bullying at work predicted $18.2 \%$ of the variance in job satisfaction in this sample, with verbal and indirect bullying the only types of bullying that contributed a significant amount of the variance. This study indicates that this issue should be closely monitored by management and addressed promptly.
\end{abstract}

Keywords: bullying, job satisfaction, professional issues, morale 


\section{BULLYING OF SCHOOL PSYCHOLOGISTS AND ITS IMPACT ON JOB SATISFACTION}

Numerous studies and professional organizations have documented the significant shortage of school psychologists in the U.S. (Morrison et al., 2020). Walcott et al. (2018) estimate a nationwide ratio of 1,381 school psychologists per student, which far exceeds the National Association of School Psychologists' (NASP) 2010 recommended maximum ratio of 1,000 school psychologists per student. This personnel deficiency has historically resulted in ongoing shortages in underserved areas, with some positions going unfulfilled for long periods of time (NASP, 2017).

In a related concern, the attrition rate for school psychologists has continued to increase. While Lund et al. (1998) estimated a 5\% annual attrition rate in 1997, Boccio and colleagues (2016) found that in a nationwide sample, $8 \%$ of respondents intended to leave the field altogether and $16 \%$ indicated a desire to leave their current position within the next five years. Subsequently, Schilling et al. (2018) reported that $19 \%$ of respondents indicated having thoughts about leaving the field and almost $22 \%$ reported leaving their current position. This trend is expected to increase with the aging of those in the profession and individuals confronting challenges to their job satisfaction through issues such as burnout (Schilling \& Randolph, 2020).

\section{Job Satisfaction in School Psychologists}

Job satisfaction is a construct that represents the degree to which people like their jobs (Spector, 1997). The working conditions for school psychologists are likely to contribute to their sense of satisfaction with their employment. Over the years, U.S. News and World Report has consistently ranked employment as a school psychologist as one of the top 100 best jobs. In fact, at the time of this writing, it is ranked $19^{\text {th }}$ in the area of best social service jobs and $27^{\text {th }}$ in the area of best STEM jobs (U.S. News and World Report, 2021). In 2006, Van Voorhis and Levinson conducted a meta-analysis of eight studies to measure job satisfaction in 2,116 school psychologists. School psychologists tended to be satisfied or very satisfied with their jobs (85\%), with the greatest satisfaction reported for relationships with coworkers, the opportunity to stay busy while working, the ability to complete independent work, and the fulfillment of providing service to others. Those areas in which school psychologists were least satisfied were with compensation, school policies and practices, and opportunities for advancement.

\section{Threats to Job Satisfaction}

Schilling et al. (2018) recently conducted a study of school psychologist burnout, which is a condition in which individuals experience feelings of physical, emotional, and mental exhaustion at work. Those experiencing burnout are at a higher risk for increased feelings of stress and emotional strain and negative perceptions of work-life balance, which may contribute to leaving an employment setting. The Schilling et al. study found that $90 \%$ participating school psychologists reported experiencing burnout at some point in their school psychology careers, which is significantly higher than the 10-15\% described in previous studies (please see Anderson et al., 1984 and Worrell et al., 2006).

Another potential threat to school psychologists' job satisfaction yet explored is the experience of being bullied at work. Although often studied in children, it also occurs among adults and in places of employment. Workplace bullying is the "systematic mistreatment" of colleagues, subordinates, or superiors that may result in social, psychological, or psychosomatic harm if the behaviors are severe or prolonged (Einarsen et al., 2011). Information from the 2017 Workplace Bullying Institute's U.S. Workplace Bullying Survey suggests that $37 \%$ of the workforce (60.3 million Americans) are either observers or victims of bullying. Bullying among adults includes the same features seen in children's peer aggression: a power imbalance, intent to cause harm, and acts that tend to be repeated over time (Olweus, 1993). Workplace bullying exists on a continuum from indirect to direct behavior (e.g., cyberbullying, indirect bullying, verbal bullying, and physical bullying). 


\section{Forms of Bullying}

Indirect bullying, including both relational and social aggression, result in damage to victims' emotional or psychological health through either threats or harm to interpersonal relationships, social status, or reputation (Crothers et al., 2019). An example of indirect bullying is being cold toward a colleague or gossiping about them with the intention to inflict harm. In the use of verbal bullying, the perpetrator intends to harm another through words (e.g., name calling, spreading rumors, not returning phone calls; Radliff, 2014). Verbal bullying in the workplace may be expressed through assigning someone an unwanted and unflattering nickname or using abusive language toward them. Physical bullying among adults is rarer than in childhood, and is more likely to occur at workplaces in which there are physical demands associated with the job. Such victimization occurs when actions (or inactions) are used against another person with the intent to harm (e.g., glaring at the individual, leaving a room when he or she enters, destroying the individual's property, making obscene gestures, and not protecting the victim's welfare; Baron \& Neuman, 1996; Radliff, 2013). Of note, recent research has suggested that cyberbullying is a separate behavior from social and relational aggression, despite previous assertions to the contrary (BLINDED, under review). In the workplace, cyberbullying may include leaving an individual off of a group email so that they miss a meeting or posting negative things about someone to a social network service.

\section{Impact of Workplace Bullying}

The results of being bullied in the workplace are significant and far-reaching (Lutgin-Sandvik \& Scheller Arst, 2014), and can be grouped into job-related and health- and wellbeing-related outcomes (Nielsen \& Einarsen, 2012). The job-related concerns include increased absenteeism and stress (Hoel et al., 2003), reduced work completion (Namie \& Namie, 2000), difficulty in concentrating on work tasks (Hall, 2019), reduced work quality and damage to job performance (Hoel et al., 2003; Vega \& Comer, 2005), low levels of work commitment (Nielsen \& Einarsen, 2012) or a reduction in job satisfaction (Nielsen \& Einarsen, 2012). Regarding their health and wellbeing, victims of workplace bullying may suffer from physical and mental health problems (Hall, 2019) and post-traumatic stress disorder (Nielsen \& Einarsen, 2012).

\section{Rationale for the Current Study}

We hypothesized that one unstudied contribution to burnout among school psychologists is the possibility of workplace bullying. A companion study was also completed studying the same question in school psychology trainers, the results for which will be published in another manuscript (BLINDED). For this investigation, we posed the following research question: Does the experience of being bullied at work account for a significant amount of the variance of the job satisfaction of school psychologists?

\section{METHODS}

\section{Participants and Procedures}

The website of every Pennsylvania public school district listed in the most recent U.S. Census was consulted to obtain the email addresses of their respective school psychologists. Such procedures yielded an overall sample of 710, of which 95 participated, representing a $13.4 \%$ participation rate. As this was not a random sample, but a total sample of school psychologists working in the public-school systems in Pennsylvania, the response rate should be considered in that light. Participants were informed the study was voluntary, and that they could withdraw from the study at any time without penalty. After agreeing to participate in the study, which was conducted prior to the COVID-19 pandemic, participants clicked on a link that transported them to the online survey tool platform.

Participants that completed the study could elect to provide their email address for entry into a $\$ 250$ Amazon gift card raffle. Eighty of the participants identified as cisgender females (84.2\%), while 15 identified as cisgender males (15.8\%). Eight-seven (91.6\%) identified as Caucasian, three (3.2\%) identified as African American, two identified as Hispanic (2.1\%), $0(0 \%)$ identified as Asian, and $0(0 \%)$ identified as Native Hawaiian or Other Pacific Islander, with three participants $(3.2 \%)$ choosing "Other" or preferring 
not to disclose their race or ethnicity. In terms of the participants' sexual orientation, 90 (94.7\%) described themselves as heterosexual, one $(1.1 \%)$ as gay, and four $(4.2 \%)$ as preferring not to answer. Only one respondent's data was excluded from the analysis due to missing values.

\section{Measure and Data Analysis Plan}

The survey included questions about participant demographics and 61 items related to workplace conditions, including workplace bullying and job satisfaction. Four questions were related to cyberbullying, indirect bullying, verbal bullying, and physical bullying within the workplace, including: 1) How often have you been bullied through technology (e.g., text messaging, Facebook, Twitter, Email, Instagram, etc.) in your position?, 2) How often have you been a target of gossip, rumors, or excluded from activities in your position?, 3) How often have you been verbally bullied in your position?, and 4) How often have you been physically bullied in your position? Participants answered through a 5-point Likert scale to respond $(1=$ Never, $2=$ Rarely, $3=$ Sometimes, $4=$ Frequently and, $5=$ Always $)$.

Participants were also asked to complete 15 items about the amount of pay they receive, their rank, the degree to which they are fairly paid for what they contribute to the organization, their prospects for promotion, the opportunities they have to advance their career, the feeling of worthwhile accomplishment they get from their work, the extent to which they can use their skills, the contribution they make to children and their families, the amount of challenge in their job, the extent to which their job is varied and interesting, what they have accomplished when they go home at the end of the day, the standard of care given to children and their families, the amount of personal growth and development they get from their work, the quality of their work with children and their families, and the amount of independent thought and action they can exercise in their work. A 5-point Likert scale $(1=$ Very Dissatisfied, $2=$ Dissatisfied, $3=$ Neither Satisfied nor Dissatisfied, $4=$ Satisfied, to $5=$ Very Satisfied) was used to capture participant responses.

We proposed one research question to examine whether the independent variables of the four different kinds of bullying predicted job satisfaction in school psychology practitioners. The predictor variables were indirect bullying, verbal bullying, physical bullying, and cyberbullying. The criterion variable was job satisfaction as measured by total score (possible range of 15 to 75) that added the values of individual items related to pay, rank, occupational opportunities available, accomplishments, contributions made, and varied and interesting employment. Multiple regression analyses were conducted to examine the relationships of the independent variables of the four types of bullying to the dependent variable, total job satisfaction.

\section{RESULTS}

Overall, school psychologists reported moderate job satisfaction $(N=94$, mean total score $=51.69, S D$ $=9.27$; mean item score $=3.45$ ). Participant responses resulted in a mean higher than 4.0 (Satisfied) in only one of the $15(6.66 \%)$ individual job satisfaction items: "The quality of my work with children and their families." Furthermore, there were two items with means in the range of dissatisfaction: "The degree to which I am fairly paid for what I contribute to this organization" and "The opportunities I have to advance my career" $(M=2.89, S D=1.16)$ and $(M=2.84, S D=.87)$, respectively.

In our study, school psychologists reported, sometimes or frequently, being the victim of indirect bullying (46.3\%), the victim of verbal bullying (37.9\%), the victim of physical bullying (0.0\%), and the victim of cyberbullying (12.6\%). In order to examine the relations among job satisfaction, indirect bullying, verbal bullying, physical bullying, and cyberbullying, Pearson's correlations were computed. Results indicated that indirect bullying $(r=-.37, p<.01)$ and verbal bullying $(r=-.34, p<.01)$ were significantly and negatively correlated with job satisfaction, while physical bullying $(r=-.02, p=.44)$, and cyberbullying $(r=-.15, p=.08)$ were negatively, but not significantly, correlated with job satisfaction. In order to examine whether different forms of bullying predict job satisfaction, a multiple linear regression was conducted. Using the enter method, it was found that the independent variables explained $18.2 \%$ of the variance and were significant predictors of job satisfaction, $F(4,93)=4.95, p<.001$. However, of the four independent variables, only indirect bullying $(\beta=-3.10, p<.001)$ and verbal bullying $(\beta=-2.81, p<.001)$ significantly contributed to the model, contributing $6.00 \%$ and $4.04 \%$ of the variance in job satisfaction, respectively. 
The analysis showed that physical bullying $(\beta=3.33, p=.376)$ and cyberbullying $(\beta=.23, p=.860)$ did not significantly predict total job satisfaction.

\section{DISCUSSION}

Workplace bullying has been identified as a significant contributor to deteriorating health and wellbeing among employees (Einarsen \& Nielsen, 2015). The presence of workplace bullying has been linked to lower job satisfaction (Hauge et al., 2010; Rodríguez-Muñoz et al., 2009) and life satisfaction (Nauman et al., 2019). Among teachers, bullying is associated with transferring schools and leaving the profession (Moon et al., 2020). Yet, the presence of workplace bullying has not yet been documented as a concern among school psychologists.

Results from this study indicate that overall, the school psychologists sampled were comparatively satisfied with their jobs in many domains of employment. These data are important as they mirror previous findings indicating school psychologists' satisfaction with their employment (Van Voorhis \& Levinson, 2006) and are consistent with the jobs ratings in U.S. News and World Report (2021). However, results also show that workplace bullying is a concern for school psychologists. The school psychologists participating in this study indicated that verbal and indirect bullying predicted a relatively large portion $(18.2 \%)$ of their job satisfaction.

The job satisfaction of participants decreased 3.10 units for every one-unit measure of indirect bullying and 2.81 units for every one-unit measure of verbal bullying. These findings reflect the findings of the limited literature regarding school psychologists' job satisfaction. Van Voorhis and Levinson (2006) found that leading predictors of school psychologists' job satisfaction include providing service to others and relationships with co-workers. It is likely that school psychologists perceive bullying victimization as interfering with their desire to serve others and have rewarding relationships with co-workers, thus negatively impacting their job satisfaction.

Further investigation is necessary to develop a more differentiated understanding of the nature of workplace bullying experienced by school psychologists. Who do school psychologists perceive as the perpetrators of their bullying victimization? In one study, among school personnel who identified as a victim of workplace bullying, $27.8 \%$ identified their perpetrator as a "same level colleague", and 57.4\% selected other, which included parents, students, administrators, etc. (Kleinheskel \& Geisel, 2019). When and where are school psychologists likely to experience bullying? When students are struggling, it is common for adults associated with a student in need to exhibit defensiveness and criticism in response to fear of being blamed for the student's difficulties (Mueller, 2017). School psychologists also experience resistance from school personnel when seeking to promote systemic change (Rogers et al., 2020). Finally, it is not uncommon for teachers to resist, overtly or covertly, consultation provided by school psychologists (e.g., Sterling-Turner et al., 2001). Further research is warranted to determine whether these common forms of resistance and defensiveness escalate to bullying.

\section{Limitations and Future Studies}

Regarding study limitations, the present findings reflect the experience of workplace bullying and job satisfaction of school psychologists in Pennsylvania. The extent to which the findings reflect the experiences of school psychologists in other states is unknown; however, we have no reason to believe that the working conditions of school psychologists in other states is appreciably different. As previously referenced, future research needs to be conducted to understand who is perpetrating the bullying against school psychologists. Finally, and importantly, this was an exploratory study and the first of its type involving school psychologists. With the current findings that workplace bullying is an issue for school psychologists, future studies may be designed to answer nuanced questions of the school psychologists that pertain to their variety of roles, daily activities, and persons with whom they work. 


\section{Implications}

The results of this study demonstrate that this sample of Pennsylvania school psychologists experience some degree of bullying at work, although the perpetrators of that bullying are presently unknown. We are left to assume that the perpetrators likely include fellow educators, whether they be teachers, administrators, fellow school psychologists, or other staff persons. This raises an interesting point when in reflecting upon anti-bullying policies in schools. Anti-bullying policies in school are generally written in reference to the behavior of students, not the educators. To the extent that professional behavior is referenced in a faculty/staff handbook, this research suggests that workplace bullying policies should be specifically included. Procedures for the reporting, investigation, and consequences of workplace bullying are important steps to address this problem for school psychologists.

The findings of this study may also be considered within the context of NASP's (2021) efforts to address the shortage of school psychologists through active retention strategies. Among other strategies, school psychologists are encouraged to: 1) develop mentorship programs, particularly for novice school psychologists, and 2) consider the existence of positive working environments as a predictor of job satisfaction. We now know that the presence of workplace bullying is a predictor of school psychologists' job satisfaction; therefore, any organizational survey of workplace environments should include the experience of bullying on the job. In turn, formal mentoring or less formal peer supervisory relationships may be ideal for support, coping, and skill building for school psychologists confronting workplace bullying.

\section{REFERENCES}

Baron, R.A., \& Neuman, J.H. (1996). Workplace violence and workplace aggression: Evidence on their relative frequency and potential causes. Aggressive Behavior, 22(3), 161-173. https://doi.org/10.1002/(SICI)1098-2337(1996)22:3<161::AID-AB1>3.0.CO;2-Q

BLINDED. (under review). Cyberbullying and indirect bullying: Two names for the same behavior?

Boccio, D.E., Weisz, G., \& Lefkowitz, R. (2016). Administrative pressure to practice unethically and burnout within the profession of school psychology. Psychology in the Schools, 53, 659-672. https://doi.org/10.1002/pits.21931

Crothers, L.M., Kolbert, J.B., Schmitt, A.J., Wells, D.R., Meidl, C., Berbary, C., . . Fidazzo, A. (2019). Cognitive predictors of relational and social bullying, overt aggression, and interpersonal maturity in a late adolescent female sample. International Journal of Bullying Prevention, 1, 136146. https://doi:10.1007/s42380-018-0001-2

Einarsen, S., Hoel, H., Zapf, D., \& Cooper, C.L. (2011). The concept of bullying and harassment at work: The European tradition. In S. Einarsen, H. Hoel, D. Zapf, \& C.L. Cooper (Eds.), Bullying and harassment in the workplace: Developments in theory, research, and practice (2 $\left.{ }^{\text {nd }} \mathrm{ed} ., \mathrm{pp} .3-39\right)$. CRC Press.

Einarsen, S., \& Nielsen, M. (2015). Workplace bullying as an antecedent of mental health problems: A five-year prospective and representative study. International Archives of Occupational \& Environmental Health, 88(2), 131-142. https://doi.10.1007/s00420-014-0944-7

Hall, T. (2019). Using transactional analysis to understand workplace bullying. Transactional Analysis Journal, 49(1), 32-42. https://doi.org/10.1080/03621537.2019.1544775

Hauge, L.J., Skogstad, A., \& Einarsen, S. (2010). The relative impact of workplace bullying as a social stressor at work. Scandinavian Journal of Psychology, 51(5), 426-433. https://doi.org/10.1111/j.1467-9450.2010.00813.x

Hoel, H., Einarsen, S., \& Cooper, C.L. (2003). Organisational effects of bullying. In S. Einarsen, H. Hoel, D. Zapf, \& C.L. Cooper (Eds.), Bullying and emotional abuse in the workplace (pp. 145-162). Taylor \& Francis.

Kleinheskel, C.J., \& Geisel, R.T. (2019). An examination of adult bullying in the K-12 workplace: Implications for school leaders. School Leadership Review, 14(1), 1-16. Retrieved from https://scholarworks.sfasu.edu/slr/vol14/iss1/7 
Lund, A.R., Reschly, D.J., \& Connolly Martin, L.M. (1998). School psychology personnel needs: Correlates of current patterns and historical trends. School Psychology Review, 27(1), 106-120. https://doi.org/10.1080/02796015.1998.12085902

Moon, B., Saw, G., \& McCluskey, J. (2020). Teacher victimization and turnover: Focusing on Different types and multiple victimization. Journal of School Violence, 19(3), 406-420. https://doi.org/10.1080/15388220.2020.1725539

Morrison, J.Q., Davies, S.C., \& Noltemeyer, A. (2020). An analysis of the workforce pipeline in school psychology. Contemporary School Psychology, 24(4). https://doi.org/10.1007/s40688-02000319-4

Mueller, T.G. (2017). Promoting collaborative partnerships in families. In J.M. Kauffman, D.P. Hallahan, \& P.C. Pullen (Eds.), Handbook of special education (2nd ed., Chapter 50). Routledge.

Namie, G. (2021). 2021 Workplace Bullying Institute US workplace bullying study. Retrieved from https://workplacebullying.org/wp-content/uploads/2021/03/2.-Affected.pdf

Namie, G., \& Namie, R. (2000). The bully at work: What you can do to stop the hurt and reclaim your dignity on the job. Sourcebooks.

National Association of School Psychologists. (2010). Model for comprehensive and integrated school psychological services.

National Association of School Psychologists. (2017). Research summaries: Shortages in school psychology: Challenge to meeting the growing needs of U.S. students and schools. Retrieved from https://www.nasponline.org/resources-and-publications/resources-and-podcasts/schoolpsychology/shortages-in-school-psychology-resource-guide

National Association of School Psychologists. (2021). Retention strategies. Retrieved from https://www.nasponline.org/resources-and-publications/resources-and-podcasts/schoolpsychology/shortages-in-school-psychology-resource-guide/retention-strategies

Nauman, S., Malik, S.Z., \& Jalil, F. (2019). How workplace bullying jeopardizes employees' life satisfaction: The roles of job anxiety and insomnia. Frontiers in Psychology, 10, 1-13. https://doi.10.3389/fpsyg.2019.02292

Nielsen, M., \& Einarsen, S. (2012). Outcomes of exposure to workplace bullying: A meta-analytic review. Work \& Stress, 26(4), 309-322. https://doi.org/10.1080/02678373.2012.734709

Olweus, D. (1993). Bullying at school: What we know and what we can do. Blackwell.

Radliff, K. (2014). Physical and verbal bullying. In J. Lipinski \& L.M. Crothers (Eds.), Bullying in the workplace: Symptoms, causes, and remedies (pp. 163-178). Routledge.

Rodríguez-Muñoz, A., Baillien, E., De Witte, H., Moreno-Jiménez, B., \& Pastor, J.C. (2009). Crosslagged relationships between workplace bullying, job satisfaction and engagement: Two longitudinal studies. Work \& Stress, 23(3), 225-243. https://doi.org/10.1080/02678370903227357

Rogers, M.R., Marracini, M.E., Lubiner, A.G., Dupont-Frechette, J.A., \& O'Bryan, E.C. (2020). Advancing advocacy: Lessons learned from advocates in school psychology. Psychological Services, 17(S1), 69-80. http://dx.doi.org.authenticate.library.duq.edu/10.1037/ser0000334

Schilling, E.J., \& Randolph, M. (2020). Voices from the field: Addressing job burnout in school psychology training programs. Contemporary School Psychology, Advance online publication. https://doi.org/10.1007/s40688-020-00283-z

Schilling, E.J., Randolph, M., \& Boan-Lezo, C. (2018). Job burnout in school psychology: How big is the problem? Contemporary School Psychology, 22, 324-331. https://doi.org/10.1007/s40688-0170138-X

Spector, P.E. (1997). Job satisfaction: Application, assessment, causes, and consequences. Sage.

Sterling-Turner, H.E., Watson, T.S., Wildmon, M., Watkins, C., \& Little, E. (2001). Investigating the relationship between training type and treatment integrity. School Psychology Quarterly, 16, 5667. https://doi.org/10.1521/scpq.16.1.56.19157

U.S. News and World Report. (2021). School psychologist overview. Retrieved from https://money.usnews.com/careers/best-jobs/school- 
psychologist\#: :text=School\%20Psychologists\%20rank\%20\%2319\%20in,we\%20rank\%20the\%2 Obest\%20jobs

VanVoorhis, R.W., \& Levinson, E.M. (2006). Job satisfaction among school psychologists: A metaanalysis. School Psychology Quarterly, 21(1), 77-90. https://doi.org/10.1521/scpq.2006.21.1.77

Vega, G., \& Comer, D.R. (2005). Sticks and stones may break your bones, but words can break your spirit. Bullying in the workplace. Journal of Business Ethics, 58, 101-109. https://doi.org/10.1007/s10551-005-1422-7

Walcott, C.M., Hyson, D., McNamara, K., \& Charvat, J.L. (2018). Results from the NASP 2015 membership survey, part one: Demographics and employment conditions. NASP Research Reports, 3(1), 1-17. 